\section{(6) OPEN ACCESS}

\title{
STOP!: a randomised, double-blind, placebo-controlled study of the efficacy and safety of methoxyflurane for the treatment of acute pain
}

\author{
Frank Coffey, ${ }_{1}$ John Wright, ${ }^{2}$ Stuart Hartshorn, ${ }^{3}$ Paul Hunt, ${ }^{4}$ Thomas Locker, ${ }^{5}$ \\ Kazim Mirza, ${ }^{6}$ Patrick Dissmann ${ }^{4}$
}

\begin{abstract}
1DREEAM: Department of Research and Education in Emergency Medicine, Acute Medicine and Major Trauma, Nottingham University Hospitals NHS Trust, Nottingham, UK ${ }^{2}$ Emergency Department, Royal Victoria Infirmary, Newcastle Upon Tyne, UK ${ }^{3}$ Emergency Department, Birmingham Children's Hospital, Birmingham, West Midlands, UK ${ }^{4}$ Emergency Department, James Cook University Hospital, Middlesbrough, UK ${ }^{5}$ Emergency Department, Barnsley District General Hospital, Barnsley, UK ${ }^{6}$ Accident and Emergency Department, Colchester Hospital University Foundation NHS Trust, Colchester, UK
\end{abstract}

\section{Correspondence to} Dr Frank Coffey, Emergency Department, Queens Medical Centre Campus, Nottingham University Hospitals NHS Trust, Nottingham, UK; Frank. Coffey@nottingham.ac.uk

Received 4 June 2013 Revised 19 February 2014 Accepted 24 February 2014 Published Online First 17 April 2014

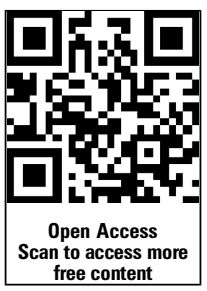

\section{SLinked}

- http://dx.doi.org/10.1136/ emermed-2014-203690

CrossMark

To cite: Coffey F, Wright J, Hartshorn $S$, et al. Emerg Med J 2014;31:613-618.

\section{ABSTRACT}

Objective To evaluate the short-term efficacy and safety of methoxyflurane for the treatment of acute pain in patients presenting to an emergency department (ED) with minor trauma.

Methods STOP! was a randomised, double-blind, multicentre, placebo-controlled study conducted at six sites in the UK. A total of 300 patients, 90 of whom were adolescent patients (age 12-17 years), were randomised 150:150 to receive either methoxyflurane via a Penthrox inhaler or placebo. The primary end point of the study was the change in pain intensity as measured using the visual analogue scale (VAS) from baseline to 5 , 10,15 and 20 min after the start of study drug inhalation. Patients were supplied with one inhaler containing $3 \mathrm{~mL}$ methoxyflurane or $5 \mathrm{~mL}$ placebo after enrolment and initial assessments. Age group (adolescent/adult) and baseline VAS score were controlled for in the statistical analyses.

Results A total of 149 patients received methoxyflurane, and 149 patients received placebo. Demographic and baseline characteristics were comparable between the groups. Methoxyflurane reduced pain severity significantly more than placebo $(p<0.0001)$ at all time points tested, with the greatest estimated treatment effect of $-18.5 \mathrm{~mm}$ (adjusted change from baseline) seen at $15 \mathrm{~min}$ after the start of treatment. Methoxyflurane was well tolerated, with the majority of adverse reactions being mild, transient and in line with anticipated pharmacological action.

Conclusion The results of this study suggest that methoxyflurane administered via the Penthrox inhaler is an efficacious, safe, and rapidly acting analgesic. Trial registration number: NCT01420159.

\section{INTRODUCTION}

Methoxyflurane belongs to the fluorinated hydrocarbon group of volatile anaesthetics and was widely used for anaesthesia during the 1960s and early 1970s. During its use as an anaesthetic, it was noted that the analgesia extended into the postoperative period, ${ }^{1}$ reducing the need for opioids. Analgesia at sub-anaesthetic doses is a feature of methoxyflurane not shared by other halogenated inhalational anaesthetics, ${ }^{2}$ and methoxyflurane continued to be given in low doses (inhaled as a vapour) for conscious analgesia as its anaesthetic use declined. The onset of action of methoxyflurane is rapid, with the onset of analgesia within 2-5 min. Analgesia persists for a period of time after cessation of inhalation.

\section{What this paper adds}

What is already known on this subject?

- There is a large volume of published literature supporting the efficacy and safety of methoxyflurane as an analgesic for trauma but evidence from randomised clinical trials has been scarce.

- Methoxyflurane can be administered through a Penthrox inhaler making it simple to use and portable.

\section{What this study adds?}

- In this multicentre, randomised, double-blind, placebo-controlled trial of trauma patients in the emergency department, methoxyflurane resulted in a significantly greater reduction in pain scores and less need for rescue medication, with initial onset of pain relief occurring at a median of $4 \mathrm{~min}$.

The major concern in the past with methoxyflurane has been nephrotoxicity, which was reported following deep methoxyflurane anaesthesia. ${ }^{3}$ Studies found that the nephrotoxicity was associated with inorganic fluoride levels, and was dose related. ${ }^{4}$ There was no evidence of nephrotoxicity associated with sub-anaesthetic doses of methoxyflurane, and the biochemical evidence demonstrated that the resulting levels of metabolites were well below levels associated with subclinical toxicity.

In 1968, Abbott Laboratories introduced the Analgizer device worldwide for low-dose selfadministration of methoxyflurane by inhalation for pain relief. This technique was used effectively and safely in obstetrics ${ }^{5-7}$ and postoperative analgesia, ${ }^{8} 9$ for analgesia during burns-dressing changes, ${ }^{10}{ }^{11}$ in the prehospital setting (Komesaroff, unpublished data; 1979), and for minor painful injuries ${ }^{12}$ or surgical procedures. ${ }^{13}$ In Australia, methoxyflurane has been used for pain relief in sub-anaesthetic doses for 33 years, and in combination with the drug delivery system Penthrox inhaler (Medical Developments International) for the last 17 years. The Penthrox inhaler, an improved version of the Analgizer, permits the use of a smaller dose to achieve adequate analgesia $(3-6 \mathrm{~mL}$ vs $15 \mathrm{~mL})$. In Australia, it is used by ambulance services, the military, firstaid officers, in ski-fields and mines, and in the 
emergency departments (EDs) of several major hospitals. It is also used for short surgical procedures such as changing dressings, biopsies ${ }^{14}$ and colonoscopies. ${ }^{15}$

Despite a large volume of published literature supporting the efficacy and safety of methoxyflurane at analgesic concentrations in both adults and children, a limited number of Good Clinical Practice (GCP) controlled studies have been conducted. Grindlay and $\mathrm{Babl}^{16}$ conducted a review of the literature on the use of methoxyflurane in EDs and prehospital settings. Their conclusions were that (1) methoxyflurane is likely to be an efficacious analgesic and (2) no significant adverse events (AEs) have been associated with it at analgesic doses. ${ }^{16}$ They state, however, that a paucity of data from controlled trials needs to be rectified, and recommend that large, blinded, placebocontrolled studies investigating its analgesic efficacy should be conducted. ${ }^{16}$

This double-blind, randomised, controlled clinical study was conducted to investigate the safety and efficacy of methoxyflurane at analgesic doses in patients aged $\geq 12$ years presenting to the ED with pain associated with minor to moderate trauma.

\section{METHODS}

STOP! was a randomised, double-blind, multicentre, placebocontrolled clinical trial conducted at six sites in the UK. Use of an active comparator, although preferred, would have posed considerable challenges to keep the study blind because of the unique mode of delivery and smell of methoxyflurane. A total of 300 patients, 90 of whom were adolescent patients (age 12-17 years), were randomised 150:150 to receive either methoxyflurane via a Penthrox inhaler or placebo.

\section{Objectives}

The primary objective of this study was to evaluate the shortterm efficacy of methoxyflurane for the treatment of acute pain in patients 12 years of age or older presenting to an ED with minor trauma (where trauma refers to 'a physical wound or injury', such as fractures, lacerations, burns, dislocations, contusions or injury due to foreign bodies). The primary end point of the study was the change in pain intensity as measured using the visual analogue scale (VAS) from baseline to 5, 10, 15 and 20 min after the start of study drug inhalation. The secondary objective was to evaluate the safety of methoxyflurane in this context.

\section{Randomisation and blinding}

A total of 300 eligible patients (210 adults and 90 adolescents) were to be randomised in a $1: 1$ ratio; 150 patients (105 adults and 45 adolescents) were each to receive either methoxyflurane or placebo. Randomisation sequences, stratified by centre and age group (adolescent/adult) were prepared by an independent statistician, and study medication was packaged according to the randomisation sequences. At enrolment, each individual patient was allocated the next randomisation number in the appropriate stratum. Treatment allocation as per the randomisation scheme was maintained by allocating study medication with the next sequential patient number. To maintain the randomisation strata for adolescents/adults, study medication for adolescents and adults were identified by different coloured labels. To prevent selection bias, the assembling and dispensing of study medication was only performed by the unblinded research team member after the patient had consented to the study. The inhalers were visually indistinguishable, but as methoxyflurane has a characteristic odour, one drop of methoxyflurane was placed on the outside of the primed inhaler to support blinding. The research nurse, the treating physician and the patient all remained blind to the treatment administered.

\section{Protocol}

Patients were supplied with one inhaler containing $3 \mathrm{~mL}$ methoxyflurane or $5 \mathrm{~mL}$ placebo as soon as possible after enrolment and initial assessment. A second inhaler containing $3 \mathrm{~mL}$ methoxyflurane or $5 \mathrm{~mL}$ placebo (depending on the treatment arm) was only supplied if requested by the patient. The research nurse assisted the patient to self-administer methoxyflurane/ placebo. It was anticipated that each inhaler could provide up to $1 \mathrm{~h}$ of pain relief when used intermittently. Patients were advised that rescue medication would be available immediately on request at any time during or after completion of their treatment with the study medication. Pain intensity (VAS) was measured 5, 10, 15, 20 and $30 \mathrm{~min}$ after the start of inhalation of study medication; thereafter it was measured every $30 \mathrm{~min}$ until rescue medication was administered or before ED discharge, whichever was sooner. Global medication performance for patient, treating physician and research nurse was assessed before ED discharge. The patients also received $16 \times 500 \mathrm{mg}$ paracetamol tablets at the time of discharge from the ED for pain relief, if required, during the 14-day post-study period. The expected duration of the study for each patient was up to 16 days, which included a 14-day post-treatment safety follow-up. Safety laboratory samples for haematology and biochemistry were drawn -10 to +5 min from the start of inhalation of methoxyflurane, as well as at the 14-day follow-up.

\section{Eligibility}

Eligible participants were 12 years of age or older who had a pain score $\geq 4$ to $\leq 7$ due to minor trauma as measured using the numerical rating scale at the time of admission and were able to give written informed consent or who were accompanied by a parent(s)/legal guardian able to provide written informed consent on their behalf.

\section{Statistical analysis}

The primary efficacy variable was the VAS pain intensity (100 mm sliding scale ruler). Change from baseline to 5, 10, 15 and $20 \mathrm{~min}$ after the start of study drug inhalation was analysed using a repeated-measures analysis of variance (using SAS proc mixed) of the difference between methoxyflurane and placebo, with unstructured covariance, adjusted for the baseline VAS score, age group (adolescent/adult) and the interaction between time point and treatment. The primary analysis was the overall test for treatment effect. The treatment effect was estimated as the average (least squares mean) difference between the methoxyflurane-treated group and the placebo group. The significance of the interaction term was also tested.

All hypothesis testing was carried out at the 5\% (two-sided) significance level unless stated otherwise. There was no other imputation of missing data in this study. If a baseline value was missing, no change from baseline was calculated. Baseline was defined as the last recorded value before the first dose.

\section{Sample size}

A sample size of 150 patients per arm provided at least $94.5 \%$ power to detect a treatment difference of $13 \mathrm{~mm}^{17}$ in change from baseline of VAS pain score after $20 \mathrm{~min}$ using repeated measures analysis of variance of assessments at 5, 10, 15 and $20 \mathrm{~min}$. Given the setting of the study, the drop-out rate was expected to be minimal, and a sample size of 150 patients per 


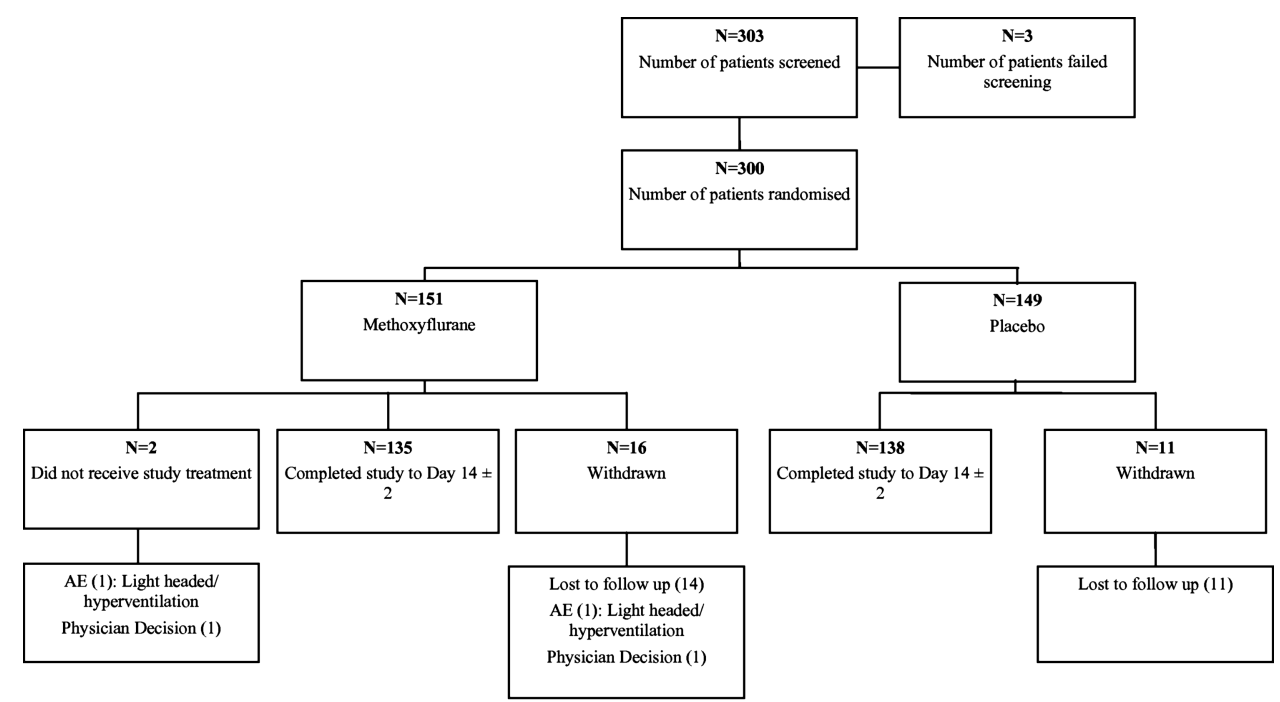

$\mathrm{N}=$ Number of patients

Figure 1 Patient disposition (all patients).

arm was considered adequate. The study population included a minimum of 90 (30\%) adolescents aged $12-18$ years.

\section{Populations analysed}

The safety population was defined as those patients who were randomised to treatment and received at least one dose of methoxyflurane or placebo. Patients who received the wrong treatment in error were analysed as treated. The intention-to-treat (ITT) population was defined as those patients in the safety population who had at least one post-baseline efficacy assessment. Patients who received the wrong treatment in error were analysed as randomised.

\section{RESULTS}

\section{Disposition of patients}

A total of 303 patients were screened for the study (figure 1). Three patients failed screening. A total of 151 patients were randomised to the methoxyflurane group and a total of 149 patients were randomised to the placebo group. Two patients randomised to the methoxyflurane group did not receive study treatment. The majority of patients in each treatment group completed the study including the 14-day safety assessments: 273 patients (91\%) (135 patients $(89.4 \%)$ in the methoxyflurane group and 138 patients (92.6\%) in the placebo group).

A total of 27 patients (9\%) did not return for the follow-up assessments: 16 patients $(10.6 \%)$ in the methoxyflurane group and 11 patients $(7.4 \%)$ in the placebo group. The most common reason for early withdrawal was the patient being lost to follow-up (25 patients, 8.3\%): 14 patients $(9.3 \%)$ in the methoxyflurane group and 11 patients $(7.4 \%)$ in the placebo group.

The first patient was dosed on 5 August 2011. The last patient to complete the study was dosed on the 26 July 2012.

\section{Demographic and other baseline characteristics}

Demographic characteristics were comparable between the methoxyflurane and placebo groups. Patients in the ITT population had a mean age of 29.1 years $(\mathrm{SD}=15.8$ years), and the majority of patients were male $(n=171 ; 57.4 \%)$ and white $(n=276$; 92.6\%) (table 1). Patients in the two treatment arms had similar
VAS scores (methoxyflurane: mean $=64.8 \mathrm{~mm}, \mathrm{SD}=16.7 \mathrm{~mm}$; placebo: mean $=64.0 \mathrm{~mm}, \mathrm{SD}=16.8 \mathrm{~mm}$; table 1 ).

Baseline injuries were also comparable between treatments (table 2). All patients $(\mathrm{N}=298)$ had somatic first injuries, with the dominant type of injury indicated as 'other' $(n=155 ; 52 \%)$, which included injuries such as wounds, soft tissue injury and muscular pain. A few patients had somatic second $(n=12)$ and third $(n=3)$ injuries.

\section{Efficacy}

The estimated mean change in VAS pain from baseline to 5, 10, 15 and $20 \mathrm{~min}$ was greater for the methoxyflurane group $(-23.1,-28.9,-34.0$ and $-35.0 \mathrm{~mm}$, respectively) than for the placebo group $(-11.3,-14.8,-15.5$ and $-19.0 \mathrm{~mm}$, respectively). Overall, there was a highly significant difference between the methoxyflurane and placebo group (estimated treatment effect, $-15.1 \mathrm{~mm}$; $95 \% \mathrm{CI}-19.2$ to -11.0 ; $\mathrm{p}<0.0001)$. The

Table 1 Demographics and baseline characteristics (intention-to-treat population)

\begin{tabular}{lccc}
\hline Characteristic & $\begin{array}{l}\text { Methoxyflurane } \\
(\mathrm{N}=149)\end{array}$ & $\begin{array}{l}\text { Placebo } \\
(\mathrm{N}=149)\end{array}$ & $\begin{array}{l}\text { Total } \\
(\mathrm{N}=298)\end{array}$ \\
\hline Age (years) & & & \\
$\quad$ Mean (SD) & $29.7(15.5)$ & $28.5(16.2)$ & $29.1(15.8)$ \\
$\quad$ Median (range) & $27(12-74)$ & $24(12-84)$ & $25(12-84)$ \\
Sex & & & \\
$\quad$ Male & $85(57.0 \%)$ & $86(57.7 \%)$ & $171(57.4 \%)$ \\
Female & $64(43.0 \%)$ & $63(42.3 \%)$ & $127(42.6 \%)$ \\
Race & & & \\
White & $140(94.0 \%)$ & $136(91.3 \%)$ & $276(92.6 \%)$ \\
Asian & $1(0.7 \%)$ & $7(4.7 \%)$ & $8(2.7 \%)$ \\
Black & $3(2.0 \%)$ & $3(2.0 \%)$ & $6(2.0 \%)$ \\
Other & $5(3.4 \%)$ & $3(2.0 \%)$ & $8(2.7 \%)$ \\
VAS score (mm) & & & - \\
$\quad$ Mean (SD) & $64.8(16.7)$ & $64.0(16.8)$ & - \\
Median (range) & $67(23-100)$ & $67(10-100)$ & - \\
\hline N, number of patients; VAS, visual analogue scale. &
\end{tabular}


Table 2 Injury details (intention-to-treat population)

\begin{tabular}{|c|c|c|c|}
\hline & $\begin{array}{l}\text { Methoxyflurane } \\
(\mathrm{N}=149)\end{array}$ & $\begin{array}{l}\text { Placebo } \\
(\mathrm{N}=149)\end{array}$ & $\begin{array}{l}\text { Total } \\
(\mathrm{N}=298)\end{array}$ \\
\hline \multicolumn{4}{|l|}{ 1st injury } \\
\hline \multicolumn{4}{|l|}{ Category } \\
\hline Somatic & $149(100.0 \%)$ & $149(100.0 \%)$ & $298(100.0 \%)$ \\
\hline \multicolumn{4}{|l|}{ Type } \\
\hline Burn & 0 & $3(2.0 \%)$ & $3(1.0 \%)$ \\
\hline Contusion & $35(23.5 \%)$ & $28(18.8 \%)$ & $63(21.1 \%)$ \\
\hline Dislocation & $2(1.3 \%)$ & $3(2.0 \%)$ & $5(1.7 \%)$ \\
\hline Fracture & $30(20.1 \%)$ & $28(18.8 \%)$ & $58(19.5 \%)$ \\
\hline Injury due to foreign body & $3(2.0 \%)$ & $1(0.7 \%)$ & $4(1.3 \%)$ \\
\hline Laceration & $4(2.7 \%)$ & $6(4.0 \%)$ & $10(3.4 \%)$ \\
\hline Other & $75(50.3 \%)$ & $80(53.7 \%)$ & $155(52.0 \%)$ \\
\hline \multicolumn{4}{|l|}{ Site } \\
\hline Face & $3(2.0 \%)$ & $1(0.7 \%)$ & $4(1.3 \%)$ \\
\hline Back & $6(4.0 \%)$ & $3(2.0 \%)$ & $9(3.0 \%)$ \\
\hline Chest & $8(5.4 \%)$ & 0 & $8(2.7 \%)$ \\
\hline Left upper limb & $24(16.1 \%)$ & $22(14.8 \%)$ & $46(15.4 \%)$ \\
\hline Left lower limb & $36(24.2 \%)$ & $34(22.8 \%)$ & $70(23.5 \%)$ \\
\hline Right lower limb & $35(23.5 \%)$ & $43(28.9 \%)$ & $78(26.2 \%)$ \\
\hline Right upper limb & $23(15.4 \%)$ & 37 (24.8\%) & $60(20.1 \%)$ \\
\hline Other & $14(9.4 \%)$ & $9(6.0 \%)$ & $23(7.7 \%)$ \\
\hline \multicolumn{4}{|l|}{ 2nd injury } \\
\hline \multicolumn{4}{|l|}{ Category } \\
\hline Somatic & $4(100.0 \%)$ & $8(100.0 \%)$ & $12(100.0 \%)$ \\
\hline \multicolumn{4}{|l|}{ Type } \\
\hline Contusion & $2(50.0 \%)$ & $5(62.5 \%)$ & $7(58.3 \%)$ \\
\hline Laceration & $1(25.0 \%)$ & 0 & $1(8.3 \%)$ \\
\hline Other & $1(25.0 \%)$ & $3(37.5 \%)$ & $4(33.3 \%)$ \\
\hline \multicolumn{4}{|l|}{ Site } \\
\hline Chest & 0 & $1(12.5 \%)$ & $1(8.3 \%)$ \\
\hline Left upper limb & $1(25.0 \%)$ & $1(12.5 \%)$ & $2(16.7 \%)$ \\
\hline Left lower limb & 0 & $2(25.0 \%)$ & $2(16.7 \%)$ \\
\hline Right lower limb & $3(75.0 \%)$ & $1(12.5 \%)$ & $4(33.3 \%)$ \\
\hline Right upper limb & 0 & $2(25.0 \%)$ & $2(16.7 \%)$ \\
\hline Other & 0 & $1(12.5 \%)$ & $1(8.3 \%)$ \\
\hline \multicolumn{4}{|l|}{ 3rd injury } \\
\hline \multicolumn{4}{|l|}{ Category } \\
\hline Somatic & $1(100.0 \%)$ & $2(100.0 \%)$ & $3(100.0 \%)$ \\
\hline \multicolumn{4}{|l|}{ Type } \\
\hline Contusion & 0 & $1(50.0 \%)$ & $1(33.3 \%)$ \\
\hline Laceration & 0 & $1(50.0 \%)$ & $1(33.3 \%)$ \\
\hline Other & $1(100.0 \%)$ & 0 & $1(33.3 \%)$ \\
\hline \multicolumn{4}{|l|}{ Site } \\
\hline Right lower limb & 0 & $1(50.0 \%)$ & $1(33.3 \%)$ \\
\hline Other & $1(100.0 \%)$ & $1(50.0 \%)$ & $2(66.7 \%)$ \\
\hline
\end{tabular}

greatest treatment effect was seen at $15 \mathrm{~min}$ (estimated treatment effect, $-18.5 \mathrm{~mm}$ ). There was no significant difference in treatment effect between age groups $(p>0.05)$. Table 3 shows the least squares mean VAS pain scores that were adjusted for baseline pain score and age group.

The majority of patients in the methoxyflurane group $(87.2 \%)$ experienced pain relief, and the median time to first pain relief was shorter than that for the placebo group (methoxyflurane, $4 \mathrm{~min}$ (95\% CI 2.0 to 5.0); placebo, $10 \mathrm{~min}$ (95\% CI 5.0 to 12.0$)$ ). The use of rescue medication (as requested by the patient) in the placebo group was significantly higher than in the methoxyflurane group (placebo, 25 patients (16.8\%); methoxyflurane, 2 patients $(1.3 \%) ; \mathrm{p}=0.0002)$. A total of 126 patients $(84.6 \%)$ in the methoxyflurane group experienced their first pain relief with $1-10$ inhalations (1-5 inhalations: $n=74$ (49.7\%); 6-10 inhalations: $\mathrm{n}=52(34.9 \%))$ in comparison with 76 patients $(51 \%)$ in the placebo group (1-5 inhalations: $n=31$ (20.8\%); 6-10 inhalations: $\mathrm{n}=45(30.2 \%))$. Patient, physician and research nurse rated methoxyflurane better than placebo $(\mathrm{p}<0.0001)$ on global medication performance, with $>80 \%$ cases in the methoxyflurane group rated as excellent, very good or good.

\section{Safety}

At least one treatment-emergent AE (TEAE: AEs that were temporally related to the study treatment) was experienced by $50 \%$ of the patients in the safety population (table 4). The most common TEAEs in both treatment groups were headache and dizziness. The proportion of patients who experienced TEAEs during the study was higher in the methoxyflurane group $(59.1 \%)$ than in the placebo group $(40.9 \%)$. The number of TEAEs in the methoxyflurane group (188 TEAEs) was higher than in the placebo group (111 TEAEs), with three TEAEs classified as severe in both groups. Only one TEAE was classified as serious, and this occurred in the methoxyflurane group. This patient experienced a lower respiratory tract infection, which resulted in hospital admittance. The lower respiratory tract infection was moderate in severity but was not related to the study drug.

Drug-related TEAEs (drug-related AEs refer to the investigator's causality assessment) were experienced by $24.8 \%$ of the patients in the safety population, with the proportion of patients experiencing drug-related TEAEs higher in the methoxyflurane group (36.2\%) than in the placebo group (13.4\%). Similarly, the number of drug-related TEAEs was higher in the methoxyflurane group (85) than in the placebo group (29). The number of patients experiencing TEAEs leading to withdrawal of study treatment was lower in the methoxyflurane group $(1.3 \%)$ than in the placebo group (2\%), with four TEAEs recorded in both the methoxyflurane and placebo group. Five patients had drug-related TEAEs that resulted in study drug withdrawal. All eight TEAEs were not serious and resolved on the same day after study drug withdrawal.

The results of the clinical laboratory evaluations showed no indication of any nephrotoxicity or hepatotoxicity.

\section{DISCUSSION}

The results of this study show that methoxyflurane is an effective analgesic compared with placebo in patients presenting with acute pain due to a variety of injuries commonly encountered in EDs. There was a highly significant difference between the methoxyflurane and placebo group $(\mathrm{p}<0.0001)$ in the analysis of the VAS pain intensity score at all time points tested, with the greatest estimated treatment effect of $-18.5 \mathrm{~mm}$ (adjusted change from baseline) seen at $15 \mathrm{~min}$ after the start of treatment. This study has demonstrated that the effect of methoxyflurane on pain is clinically significant, as it reduced pain severity by more than $30 \% .^{18}$ In addition, the median time to first pain relief for the methoxyflurane group was $4 \mathrm{~min}$. This compares favourably with a median time to onset of meaningful pain relief of $11 \mathrm{~min}$ with intranasal fentanyl (IF), ${ }^{19} 16 \mathrm{~min}$ with oromucosal fentanyl, ${ }^{19}$ and 5 min with intravenous morphine sulfate. ${ }^{20}$ There was a higher occurrence of AEs in methoxyflurane-treated patients than in those treated with placebo; however, in general, methoxyflurane was well tolerated, with the majority of adverse reactions being mild, transient 
Table 3 Analysis of visual analogue scale (VAS) pain intensity score (intention-to-treat population): adjusted change from baseline

\begin{tabular}{|c|c|c|c|c|}
\hline & Methoxyflurane (N=149) & Placebo $(N=149)$ & Estimated treatment effect $(95 \% \mathrm{Cl})$ & $\mathrm{p}$ Value \\
\hline \multicolumn{5}{|c|}{ Adjusted* change from baseline $(\mathrm{mm})$} \\
\hline Overall & -30.2 & -15.2 & $-15.1(-19.2$ to -11.0$)$ & $<0.0001$ \\
\hline $5 \mathrm{~min}$ & -23.1 & -11.3 & $-11.8(-15.6$ to -8.0$)$ & \\
\hline $10 \mathrm{~min}$ & -28.9 & -14.8 & $-14.1(-18.4$ to -9.8$)$ & \\
\hline $15 \min$ & -34.0 & -15.5 & $-18.5(-23.4$ to -13.5$)$ & \\
\hline $20 \mathrm{~min}$ & -35.0 & -19.0 & $-16(-21.3$ to -10.7$)$ & \\
\hline Time by treatment interaction & & & & 0.0019 \\
\hline
\end{tabular}

and in line with anticipated pharmacological action. The majority of patients successfully completed treatment, with no relevant difference in incidence, severity, or proportion of events leading to withdrawal between the methoxyflurane and placebo groups.

The rapid pain relief provided by methoxyflurane has also been reported by Johnston et $a l,{ }^{21}$ who found in a retrospective, observational prehospital study of 1024 patients that Penthrox provided a more rapid onset of pain relief than IF, and as a sole agent was not associated with any AEs, whereas IF was implicated in several patients becoming hypotensive. There is also evidence that methoxyflurane provides analgesia that is greater than or equal to that of Entonox. ${ }^{22}$ In a prospective, randomised, crossover study that compared nitrous oxide with Penthrox in 20 dental patients, ${ }^{23}$ there were minimal adverse effects with either gas, with the number of AEs similar between treatments.

Chin et $a l^{24}$ conducted a pilot randomised, double-blind, placebo-controlled trial to evaluate the efficacy of using Penthrox inhaler for acute pain relief in children with upper limb fracture. They reported that there was a significantly greater reduction in pain score $(4.0$ vs $1.3 ; \mathrm{p}<0.05)$ in patients using the Penthrox inhaler than those treated with placebo. In a related study, McCaskill et al (unpublished data; 2002) evaluated the effectiveness of methoxyflurane via an inhaler (brand not stated) in children with isolated upper limb fractures, and also in children undergoing venepuncture, in a randomised, double-blind, placebo-controlled trial. In the venepuncture group, there was no significant difference in the median change in pain scores during the procedure, and no increase in the proportion of children in the methoxyflurane-treated group with unchanged or improved pain scores. In contrast, in the upper limb fracture component of the study, children receiving methoxyflurane had significantly improved median change in pain scores compared with those receiving placebo. Spruyt et $a l^{25}$ conducted a randomised, double-blind, single-centre, placebo-controlled study to assess the safety and efficacy of Penthrox for the treatment of incident pain in adult patients undergoing a bone marrow biopsy. The results indicated that methoxyflurane significantly improved mean worst pain overall $(p=0.011)$, and significantly improved pain during the aspiration component $(p=0.001)$. Although the number of AEs was significantly higher in the Penthrox than the placebo arm, most AEs were mild, and there was no difference in the number of serious AEs in the two treatment arms. No serious AEs were considered to be related to the study drug.

The main limitation of the present study is the fact that an active comparator was not included in the design. The use of an active comparator, although preferred, would have posed insurmountable challenges to keep the study blind because of the unique mode of delivery and smell of methoxyflurane. The study design therefore included a placebo (normal saline) comparison to ensure that patient, physician and research nurse blinding was maintained.

In conclusion, the results of this study support the evidence found in previous trials that methoxyflurane used as an analgesic is efficacious and safe. Although it appears to cause more adverse reactions than placebo, this is to be expected given its pharmacological action, and all such reactions have been found to be mild and transient.

Table 4 Treatment-emergent adverse events (safety population)

\begin{tabular}{|c|c|c|c|c|c|c|}
\hline & \multicolumn{2}{|c|}{ Methoxyflurane $(\mathrm{N}=149)$} & \multicolumn{2}{|c|}{ Placebo $(\mathrm{N}=149)$} & \multicolumn{2}{|c|}{ Total $(\mathrm{N}=298)$} \\
\hline & $\mathbf{n}$ & N (\%) & $\mathbf{n}$ & N (\%) & $\mathrm{n}$ & N (\%) \\
\hline TEAEs & 188 & $88(59.1 \%)$ & 111 & $61(40.9 \%)$ & 299 & $149(50.0 \%)$ \\
\hline Severe TEAEs* & 3 & $2(1.3 \%)$ & 3 & $2(1.3 \%)$ & 6 & $4(1.3 \%)$ \\
\hline Serious TEAEst & 1 & $1(0.7 \%)$ & 0 & 0 & 1 & $1(0.3 \%)$ \\
\hline Drug-related TEAEsł & 85 & $54(36.2 \%)$ & 29 & $20(13.4 \%)$ & 114 & $74(24.8 \%)$ \\
\hline TEAEs leading to withdrawal of study drug§ & 4 & $2(1.3 \%)$ & 4 & $3(2.0 \%)$ & 8 & $5(1.7 \%)$ \\
\hline
\end{tabular}

$\mathrm{n}$, number of events; $\mathrm{N}$, number of patients; $\%$, percentage of patients.

*Severity classified as 'severe' or missing.

tSerious classified as 'yes' or missing.

¥Relationship to study drug classified as 'related' or missing; serious drug-related TEAEs were both serious and drug-related, as specified above.

$\S$ Action taken that was classified as 'drug withdrawn'.

TEAE, treatment-emergent adverse event. 
Acknowledgements The authors would like to thank Mark Roberts of ORION Clinical Services for editorial assistance.

Contributors FC was involved in study design development, patient screening and data acquisition and assisted in writing and reviewing the manuscript for important intellectual content. JW was involved in patient screening and data acquisition and assisted in writing and reviewing the manuscript for important intellectual content. SH was involved in trial methodology and data acquisition and assisted in writing and reviewing the manuscript for important intellectual content. PH was involved in data acquisition and assisted in writing and reviewing the manuscript for important intellectual content. TL was involved in the recruitment of patients to the study and their clinical care. He also contributed to the writing and review of the manuscript for important intellectual content. KM was involved in patient recruitment and data acquisition and assisted in writing and reviewing the manuscript for important intellectual content. PD was involved in data acquisition and assisted in writing and reviewing the manuscript for important intellectual content.

Funding The study was funded by Medical Developments International (MDI).

Competing interests $\mathrm{FC}$ was paid travel and subsistence expenses by MDI for one investigator's meeting. All author's institutions were paid by MDI to run the study; there were no other competing interests.

Ethics approval The study was conducted according to the clinical study protocol, the current International Conference on Harmonisation (ICH) Good Clinical Practice (GCP) guidelines, any local guidelines, and the Declaration of Helsinki (the 18th World Medical Assembly in Helsinki (1964) with the additions from the 29th, 35th, 41st, 48th and 52nd World Medical Assemblies (Tokyo 1975, Venice 1983, Hong Kong 1989, Somerset West 1996, Edinburgh 2000, Washington 2002, Tokyo 2004 and Seoul 2008)). Any changes to the study design were formally documented in a protocol amendment and approved by each centre's independent ethics committee.

Provenance and peer review Not commissioned; externally peer reviewed.

Open Access This is an Open Access article distributed in accordance with the Creative Commons Attribution Non Commercial (CC BY-NC 3.0) license, which permits others to distribute, remix, adapt, build upon this work non-commercially, and license their derivative works on different terms, provided the original work is properly cited and the use is non-commercial. See: http://creativecommons.org/ licenses/by-nc/3.0

\section{REFERENCES}

1 Stephen CR. Clinical applications of methoxyflurane. Acta Anaesthesio/ Scand Supp/ 1966:24:215-22

2 Tomi KT, Mashimo T, Tashiro C, et al. Alterations in pain threshold and psychomotor response associated with subanaesthetic concentrations of inhalation anaesthetics in humans. Br J Anaesth 1993;70:684-6.

3 Crandell WB, Pappas SG, Macdonald A. Nephrotoxicity associated with methoxyflurane anaesthesia. Anesthesiology 1966;27:591-607.

4 Mazze R, Cousins M. Biotransformation of methoxyflurane. Int Anesthesiol Clin 1974:12:93-105.

5 Bergsjo $\mathrm{P}$, Lindbaek E. Comparison between nitrous oxide and methoxyflurane for obstetrical analgesia. Acta Obstet Gynecol Scand 1971:50:285-90.
6 Fielding $M E$, Hurry DJ. Analgesia in instrumental vaginal delivery by the intermittent self-administration of methoxyflurane using a disposable vaporizer. $\mathrm{Br} J$ Anaesth 1972;44:386-90.

7 Marx GF, Chen LK, Tabora JA. Experiences with a disposable inhaler for methoxyflurane analgesia during labour: clinical and biochemical results. Can Anaesth Soc J 1969;16:66-71.

8 Yakaitis RW, Cooke JE, Redding JS. Self-administered methoxyflurane for postoperative pain: effectiveness and patient acceptance. Anesth Analg 1972;51:208-12.

9 Yakaitis RW, Redding JS. Self-administered methoxyflurane for improved postoperative ventilation. Anesth Analg 1970;49:345-50.

10 Packer KJ. Methoxyflurane analgesia for burns dressings. Postgrad Med $\mathrm{J}$ 1972;48:128-32.

11 Packer KJ, Titel JH. Methoxyflurane analgesia for burns dressings: experience with the analgizer. Br J Anaesth 1969;41:1080-5.

12 Romagnoli AL, Busque L, Power DJ. The "analgizer" in a general hospital: a preliminary report. Can Anaesth Soc J 1970;17:275-8.

13 Lewis LA. Methoxyflurane analgesia for office surgery. Surgical gem. J Dermatol Surg Oncol 1984;10:85-6.

14 Grummet J, Huang S, Konstantatos A, et al. The 'green whistle': a novel method of analgesia for transrectal prostate biopsy. Br J Urol 2012;110(Suppl):85-8.

15 Nguyen NQ, Toscano L, Lawrence M, et al. Patient-controlled analgesia with inhaled methoxyflurane versus conventional endoscopist-provided sedation for colonoscopy: a randomized, multi-centre trial. Gastrointest Endosc 2013:78:892-901.

16 Grindlay J, Babl FE. Review article: efficacy and safety of methoxyflurane analgesia in the emergency department and prehospital setting. Emerg Med Australas 2009;21:4-11.

17 Gallagher EJ, Liebman M, Bijur PE. Prospective validation of clinically important changes in pain severity measured on a visual analog scale. Ann Emerg Med 2001;38:633-8

18 Farrar JT, Young JP Jr, LaMoreaux L, et al. Clinical importance of changes in chronic pain intensity measured on an 11-point numerical pain rating scale. Pain 2001;94:149-58.

19 Chaplain S, Zeppetella G. Instanyl: intranasal fentanyl for treating breakthrough pain. Prescriber 2010;19:40-1.

20 Tveita T, Thoner J, Klepstad P, et al. A controlled comparison between single doses of intravenous and intramuscular morphine with respect to analgesic effects and patient safety. Acta Anaesthesiol Scand 2008;52:920-5.

21 Johnston S, Wilkes GJ, Thompson JA, et al. Inhaled methoxyflurane and intranasal fentanyl for prehospital management of visceral pain in an Australian ambulance service. Emerg Med J 2011;28:57-63.

22 Tomlin PJ, Jones BC, Edwards $\mathrm{R}$, et al. Subjective and objective sensory responses to inhalation of nitrous oxide and methoxyflurane. Br J Anaesth 1973;45:719-25.

23 Abdullah WA, Sheta SA, Nooh NS. Inhaled methoxyflurane (Penthrox) sedation for third molar extraction: a comparison to nitrous oxide sedation. Aust Dent J 2011;56:296-301.

24 Chin R, McCaskill M, Browne $G$, et al. A randomised control trial on inhaled methoxyflurane pain relief, in children with upper limb fracture. J Paediatr Child Health 2002:38:A13-14.

25 Spruyt 0 , Westerman D, Milner A, et al. A randomised, double-blind, placebo-controlled study to assess the safety and efficacy of methoxyflurane for procedural pain of a bone marrow biopsy. BMJ Support Palliat Care 2013; Published Online First: 7 June 2013 doi: 10.1136/bmjspcare-2013-000447 